\title{
A Review of Soil Nailing Design Approaches
}

\author{
S.N.L. Taib ${ }^{1}$
}

\begin{abstract}
A number of design manuals and recommendations; namely by the HA 68 [4] (U.K.), BS8006 [1] (U.K.), RDGC [7] (France) and FHWA [5] (USA) are available for soil nailing. This paper will focus on the different approaches, specifically on the assumptions made for the design of soil nailing structures.
\end{abstract}

Keywords: Soil nailing, BS8006, HA 68

\section{INTRODUCTION}

oil nailing is a relatively new method, which has been used for over 3 decades for soil reinforcement purposes.

It is an in-situ earth reinforcing method, in which the primary applications are to retain excavations or cuts and to stabilise slopes. The principal reinforcing materials, the nails, are inserted into the earth as passive inclusions providing reinforcement to the earth that help the earth structure to gain its overall strength. A factor, which makes soil nailing technique more desirable than other earth reinforcing methods when performed on cuttings or excavations, is its easy and flexible top-down construction (excavation, nail installation and placement of shotcrete) as shown in Figure 1.

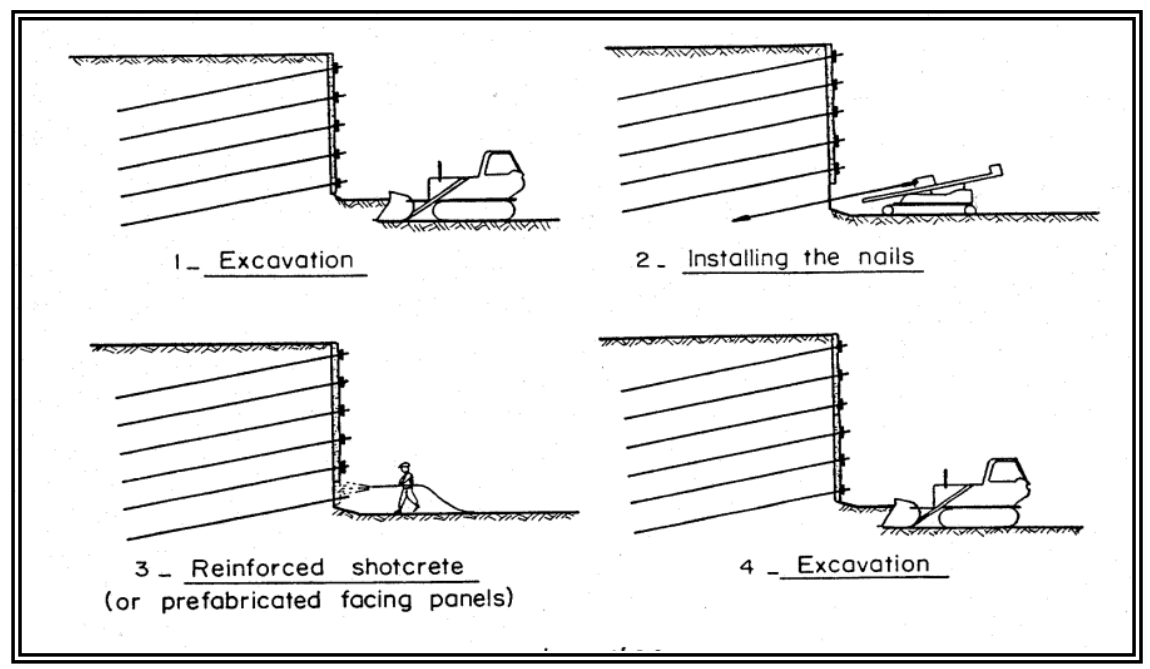

Figure 1 The three stages of soil nailing construction process [7].

${ }^{1}$ Senior Lecturer, Department of Civil Engineering, Faculty of Engineering, Universiti Malaysia Sarawak. 


\section{DESIGN ACCORDING TO HA 68 [4]}

The Department of Transport of the UK [4] employs the limit state principles incorporating partial safety factors as suggested by [3] for geotechnical engineering design. Any design is based on ultimate and serviceability limit states. The ultimate limit state occurs when a collapse mechanism forms, while, the serviceability limit state might occur during the working or service condition of the structure in which a situation such as movement in the structure may affect the functionality of the structure or of the adjacent structures or services.

HA 68 gives a single unified effective stress design approach for all types of reinforced highway earthworks with slope angles to the horizontal in the range $10^{\circ}$ to $70^{\circ}$, and soil types in the strength range $\phi=15^{\circ}$ to $50^{\circ}$. Values of c' may be included, as well as pore water pressures and limited uniform surcharge applied at the top of the slope.

A limit equilibrium approach is adopted based on a two-part wedge mechanism with the inclusion of partial safety factors. Figure 2 shows the geometry of HA 68's two-part wedge mechanism. Equilibrium is reached when the driving forces, which consist of the self weight of the structure and surcharge loads multiplied with the load partial factor (of predetermined value of unity) are in equilibrium with the resisting forces which are the shear strengths of soil and the reinforcement forces divided by the material partial safety factors of predetermined values suggested by Department of Transport. The assumption is made that the nails' contribution is purely axial. Shear stress and bending stiffness are ignored in this design.

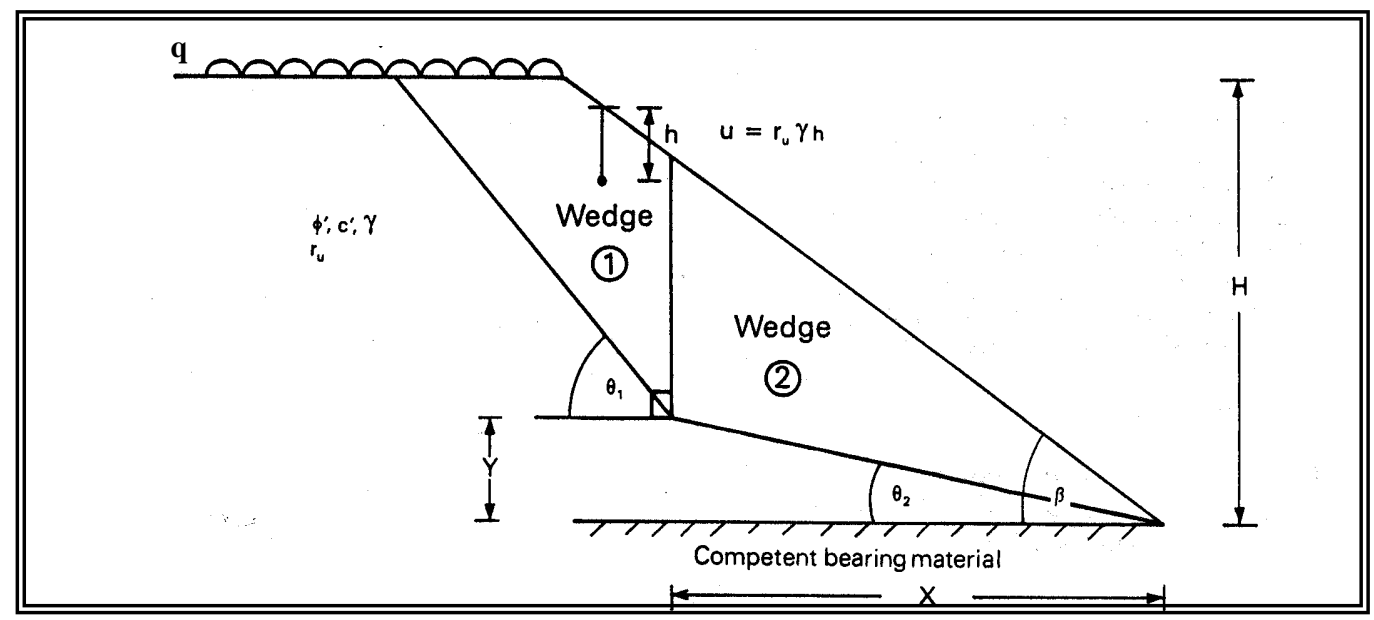

Figure 2: Geometry of HA68's two-part wedge mechanism [4].

According to Department of Transport, the two-part wedge mechanism is preferable to a log spiral mechanism because it provides a simple basis for obtaining safe and economical solutions and is particularly suitable for reinforced soil including soil nailed structures. It is inherently conservative when compared to more exact solutions but allows simple hand check calculations to be carried out. Two two-part wedges are introduced in this manual that are the $\mathrm{T}_{\max }$ and $\mathrm{T}_{\mathrm{o}}$ mechanisms. The $\mathrm{T}_{\max }$ mechanism identifies the location in the structure, which needs the maximum total horizontal reinforcement, meanwhile, the $T_{0}$ mechanism is one where no reinforcement is needed. For inclined reinforcement (when angle of nail inclination, $\delta \neq 0$ ) the variables for these mechanisms are presented as $\mathrm{T}_{\max \delta}$ and $\mathrm{T}_{\mathrm{o} \delta}$ (refer to Figure 3 ).
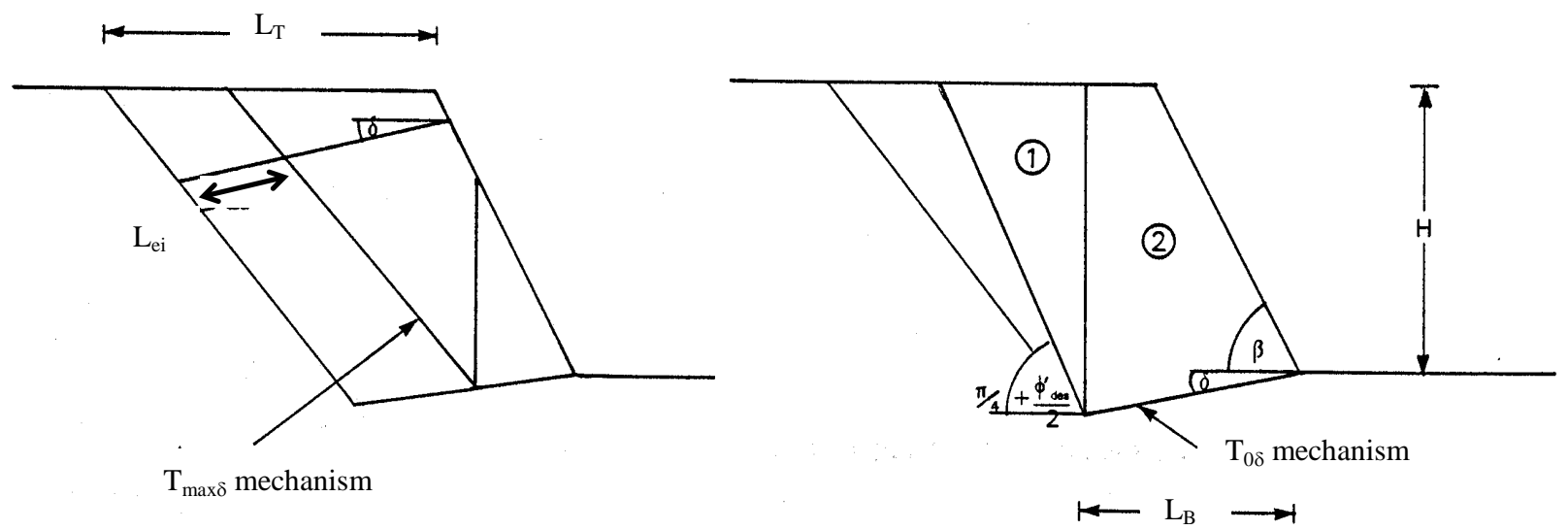

Figure 3: $\mathrm{T}_{\max \delta}$ and $\mathrm{T}_{\mathrm{o} \delta}$ mechanisms [4] 
For inclined reinforcement, the values of $\mathrm{T}_{\max \delta}$ and $\mathrm{P}_{\text {des }}$ shall be determined next. $\mathrm{T}_{\max \delta}$ value is the total reinforcement force inclined at angle $\delta$ for most critical two-part wedge mechanism; while, $\mathrm{P}_{\text {des }}$ is the design nail capacity per metre length of slope, based on the rupture strength of the reinforcement or pullout capacity of the reinforcement. HA68 in Section 2.23 on page $2 / 4$ comments that the strength mobilised in the reinforcement is taken to be the lesser of the design rupture strength and the design pullout resistance of the length of reinforcement beyond the failure surface $\left(\mathrm{L}_{\mathrm{e}}\right)$ whenever the failure surface cuts a layer of reinforcement or row of nails. The lesser value is chosen to govern the design since this is the value that becomes critical at failure.

The Department of Transport suggests nails of the same strength capacity to be utilised for reinforcing the slope. The number of reinforcements per unit length, $\mathrm{N}_{\mathrm{n}}$, not including the basal layer is directly obtained from the values of $\mathrm{T}_{\max \delta}$ and $\mathrm{P}_{\mathrm{des}}$, where

$\mathrm{N}_{\mathrm{n}}=\mathrm{T}_{\max \delta} / \mathrm{P}_{\mathrm{des}}$

(Equation 1)

Due to this assumption, of similar capacity to all the nails, the manual suggests optimum variable vertical layer spacing due to the requirement to avoid local over-stressing of any layer of reinforcement, which would later introduce progressive failure of the whole structure; especially for reinforcement having identical capacity. In HA68 designs, the total reinforcement force increases parabolically down to the bottom of the structure and the decrease in vertical spacing going down the slope is seen as desirable to avoid local instability. The equation that governs the spacing is

$\mathrm{zi}=\left[\sqrt{ }(\mathrm{i}-1) / \mathrm{N}_{\mathrm{n}}\right] \times \mathrm{H}$

(Equation 2)

where

$\mathrm{zi}=$ depth of ith layer of reinforcement below crest of slope.

Now that once the $\mathrm{T}_{\max \delta}, \mathrm{T}_{\mathrm{o} \delta}$ mechanisms are located and total number of reinforcements $\left(\mathrm{N}_{\mathrm{n}+1}\right)$ are obtained, a drawing of the soil nailed structure's profile can be designed. In general, HA 68 gives a step by step design procedure for soil nailing.

\section{DESIGN ACCORDING TO BS 8006 [1]}

In the design approach of BS 8006, the limit state principle is again adopted. The limit equilibrium approach is applied wherein the internal as well as the external stabilities of structure are checked against the limit states. As in HA68, in order to be consistent with suggestions in [3], partial safety factors are included in its design calculation. The design of soil nailed structure in existing ground is presented in Section 7 (Design of Reinforced Slopes) of the standard, while design of soil nailing wall is presented as part of Section 6. (Design of Walls and Abutments)

BS 8006 is more comprehensive than HA 68 in its explanation of the available approaches and assumptions from which the designer can choose. A comprehensive list of suitable load partial factors and material partial factors is given and these are related to different construction conditions and situations. Two methods of searching for the critical failure are presented the two-part wedge (as in HA 68) and the log spiral method. BS 8006 advises its users to include shear resistance along with the known tensile reinforcement provided by the nails if the resistance is significant.

BS 8006 suggests the stages that designer can follow in soil nailed structures design; which are:

1. The determination of the position of the critical slip surface and the resisting force or moment to maintain equilibrium of the active zone.

2. The determination of the tensile and shear loads for an initial constant spacing and inclination of nails of constant stiffness and length.

3. A check for each level, allowing for stages of construction, against failure due to

a. tension in the nail at the slip surface,

b. pullout of the length of nail in the resistant zone,

c. bending and shear in the nail near the slip surface, and

d. bearing failure of soil against the nail.

The designer can now select a new and improved pattern and disposition of nails and re-analyse. It should be noted here that the shear loads in the nails can be obtained from [8] and [7] in which according to BS 8006, a technique based on maximum plastic work with limits placed on the allowable lateral earth pressure on the nails and bond resistance is applied. Another method to look for shear loads is introduced by [2] where they adopted the theory of deflection of laterally loaded narrow piles to determine nail deflections and kinematical compatibility to determine the value of resulting shear forces in the nails. 
BS 8006 gives more freedom in many aspects of choosing the most suitable design approach rather than HA 68, which is more directive. It depends on the experience and the knowledge of the designer in choosing the appropriate approaches suitable design with guidance from the design manual.

\section{RECOMMENDATIONS BY RDGC [7] (PROGRAM CLOUTERRE)}

The French initiated the Clouterre program in 1986 [7], jointly funded by the French government and private industry, with a budget of the order of $\$ 4$ million and with 21 individual private and public participants. The program involved three largescale experiments in a prepared fill of Fontainebleau sand and the monitoring of six full-scale in-service structures. The results of the Clouterre program have been published and form the basis for soil nailing design approach adopted in France.

The report by RDGC on the program does not specifically provide a step-by-step procedure to design a soil nailed structure as presented in HA68. It sets up guidance on design and special criteria that must be considered. A designer is recommended to start with a preliminary design that will enable him or her to later define essential characteristics of the structure, such as the resistance values, lengths and spacings required in the final design. Preliminary design charts are used to seek for the characteristics mentioned above at the simplest condition of the structure; for example, identical nails are evenly distributed, homogeneous soil and nails working only in tension. Several design charts are presented in the report i.e. [6].

The report elaborates on the principles used to assess stability of soil nailed structures. In accordance with [3], for geotechnical design, and as can be seen in HA 68 and BS 8006, the conventional global safety factor is replaced by partial resistance and load factors. Apart from that, suggestions on characteristic values of the loads and resistances are also presented. The characteristic value is defined as the ratio of average value and the distribution coefficient. The coefficient is applied to make sure that a minimal probability is not achieved. The report mentions that analysis of stability and design of soil nailing can be done at both the ultimate limit state and the serviceability limit state.

The limit equilibrium method and the finite element method are suggested as the basis for stability analysis and design of soil nailing. Limit equilibrium method includes an examination on the equilibrium between the soil and the strength of materials used in the slope, while the finite element method is used to calculate the amount of deformation that the structure will have (to check whether it is either below or beyond a certain acceptable threshold value). Due to unavailability of a mean to calculate the deformation in slope in this report, the design is limited to the limit equilibrium method which has to be checked not only when structure is completed but also during each phase of construction.

The report presents 4 types of failure modes based on scaled-down laboratory models tested to failure, which are breakage of the nails, lack of friction between the soil and nails, instability during excavation process and overall sliding of the reinforced soil mass. These failure modes which are observed in laboratory models, justified the use of limit equilibrium in designing soil nailed structures as all these failures involved slip surfaces (except for the lack of friction case). A second justification on the use of limit equilibrium method is given by two actual structures, which failed and exhibited pullout and tensile failures respectively. Safety factor was checked by analysing the potential failure surfaces and was found to be near unity.

An interesting point that is included in the report concerns the assumption made in any limit equilibrium calculation on the simultaneous mobilisation of resistances. These resistances are the resistances of the nail, particularly its tensile strength, shear resistance in the soil, pullout resistance of the nail (limit skin friction, $f_{\max }$ ) and passive pressure at failure of the soil normal to the nail, which in actual condition do not act simultaneously in the structure. Further justification on this has to be done through experimental work in order to gain more confidence on the use of the limit equilibrium method in soil nailing design. However, according to the report, the assumption on simultaneous mobilisation of resistances is, in spite of everything, still a good approximation of the actual-and complicated-behaviour of soil nailed walls.

\section{DESIGN ACCORDING TO FHWA [5]}

As with other design approaches, the FHWA also applies limiting equilibrium method in its soil nailing design. Specifically, the manual utilises the slip surface limiting equilibrium method which is used by all current practical design methods of soil nailing. Two limit states, as with the other design recommendations, are considered, namely, the strength limit state (ultimate limit state) and the service limit state. Another limit state known as extreme limit state, which belongs to the strength limit state, recognises structure under extreme loads such as seismic loading.

The manual recognises the benefits of utilising the slip surface limiting equilibrium method compared to the earth pressure method and these are summarised as below;

To date, virtually all designers have utilised the approach and there are no current empirical earth pressure recommendations sufficient to handle the variety of conditions faced in soil nailing such as soil types, geometries and loading. 
Several factors inherited by soil nailing technique; for example, heterogeneity of soils introduces complexity in the use of earth pressure method in soil nailing.

Another drawback of using the earth pressure system is the definition of locations of the maximum tension line for each of the reinforcements. Again, it is particularly complex to define these locations due to the variety of conditions encountered in soil nailing since the definition of these locations is dependent on the geometry of the system, character of reinforcements and distribution of applied loading. A soil nailed structure, will have a wide range of soil shear strengths and soil / grout bond capacities.

The manual introduces two approaches to design, which are the Service Load Design (SLD) and the Load and Resistance Factor Design (LRFD), which consider both limit states in their calculations. In SLD, allowable nail loads (tendon strength and pullout resistance of nail) are suggested for the reinforcement strength and recommended factors of safety are applied to the soil strength at both limit states in which the allowable nail loads and factored soil strengths exceed the applied loads. In contrast, in LRFD, at strength limit state, the soil and nail design strengths which are obtained by applying resistance factors to their ultimate strengths, exceed the applied loads which are multiplied by load factors. In service limit state analysis for both designs, overall displacement of the structure is recognised and in certain cases, on the facing, the crack width has to be observed to be within specified limits. This manual provides guidance on finding the displacements (i.e. maximum lateral movements in different soil types) for consideration in the service limit state analysis.

To consider the strength limit state, all potential modes should be considered; the external modes (that do not specifically intersect the reinforcement), the internal modes (i.e. failure either due to rupture of reinforcement or failure of facing) in which the global failure surface intersects the reinforcement and the mixed modes which includes internal mode failure and where some part of the failure surface does not touch the reinforcement. The local stability of the facing during excavation is also highlighted in the manual since this failure cannot be directly assessed using the conventional stability analysis.

A matter to point out from this manual is the reinforcing effect of the nail. The nail is seen to contribute three reinforcing effects which are the rupture strength of the tendon, the pullout resistance and an additional effect not considered in other design manuals, which is the nail head connection to the facing. The manual continues to state that the nail contribution to the stability of the structure must be the least of three values namely, the tensile strength of the nail, pullout resistance of the length of the nail beyond the slip surface, and the nail head strength plus the pullout resistance of nail's length between the head and the slip surface.

Design of soil nails and wall facing is treated as a combined integrated soil-nail-wall "system". This is an effort to ensure that the design could suffice for long-term usage. This manual does not include the shear and bending contributions of the nail and only considers the tensile strength. The other contributions are neglected due to the reason that their mobilisations only after significant deformation in the structure and this assumption, according to the manual, is conservative.

Before establishing detailed design calculations, the designer has to choose the wall layout and dimensions (i.e. considering the environment in the vicinity of the location) together with the ground material properties and the subsurface properties in order to determine the preliminary nail pattern which includes nail lengths, locations, spacings, strengths and inclinations. As a starting point, a uniform inclination of $15^{\circ}$ is suggested for nails installed in predrilled holes (inclination of lower than $5^{\circ}$ should not be used since grouting will be particularly difficult). Uniformity also applies to the spacings, length (normally in the range of 0.6 to 1 times the height of the wall for cut slopes with modest backslopes and minimal surcharge loadings) and size of the nails. The nail lengths and required strengths are exposed to the same limiting factors as the nail spacing. They will increase in the presence of lower soil strengths, lower nail-ground pullout resistances, steeper face and backslope angle and higher surcharge loadings, which will alter the preliminary pattern. With the preliminary design, designer can check for stability and make necessary alterations in order to obtain a more satisfactory detailed design.

\section{CONCLUSIONS}

This paper reviews soil nailing design suggestions and manuals [HA68 [4] (U.K.), BS8006 [1](U.K.), RDGC [7] (France) and FHWA [5] (USA)]. Theories on the mechanics of the technique were presented. General conclusions of this paper are:

- All methods employ the limiting equilibrium analysis and in some methods, use of partial safety factors is evident.

- In the limiting equilibrium analysis, concern on the assumption made on the simultaneous mobilisation of resistances should be addressed.

- HA 68 allows the users to follow step by step procedures in designing a soil nailed structure as opposed to the other manuals (i.e. BS 8006 in which users are given various design suggestions for them to consider).

- The straightforward approach in HA 68, allows a spreadsheet program for designing to be produced. The design was applicable for up to ten reinforcements and for simple design of soil nailing. A proper method of finding the $\mathrm{T}_{\mathrm{o}}$ mechanism still needs to be established for program HA 68 Design.

- It would be beneficial if more empirical data (i.e. pullout tests on nails) are included in these manuals for reference. 
- The general failure mechanisms in soil nailing as provided in the manuals are tensile failure in the nail at the slip surface, pullout of the length of nail in the resistant zone, bending and shear in the nail near the slip surface, bearing failure of soil against the nail, instability during excavation process and overall sliding of the reinforced soil mass. However, FHWA does not include the shear and bending contributions of the nail and only considers the tensile strength. The other contributions are neglected due to their mobilisations only after significant deformation in the structure and this assumption, according to the manual, is conservative.

- Clouterre recommends that limit equilibrium method has to be checked not only when structure is completed but also during each phase of construction.

- FHWA includes extreme limit state which belongs to the strength limit state, recognises structure under extreme loads such as seismic loading.

- An additional effect not considered in other design manuals, which is the nail head connection to the facing, is included in FHWA manual.

- Further work on estimating amount of displacements on soil nailing structure is recommended and shall complement the limiting equilibrium analysis.

\section{REFERENCES}

[1] BSI (1995), BS 8006, British Standard Code of Practice for Strengthened/Reinforced Soils and Other Fills.

[2] Bridle, R.J. and Barr, B.I.G. (1990), The Analysis and Design of Soil Nails, Proceedings of the International Reinforced Soil Conference, Glasgow, 10-12 September 1990, Thomas Telford, London, pp. 249-254.

[3] CEN (1999), Eurocode 7: Geotechnical Design, ENV 1997-1:1999 - Part 1, General Rules, European Committee of Standardisation.

[4] Department of Transport, HA 68, Design Methods for the Reinforcement of Highway Slopes by Reinforced Soil and Soil Nailing Techniques. (1994)

[5] FHWA (1996), FHWA/SA-96/069 Manual For Design and Construction Monitoring of Soil Nail Walls (Technical Manual 1994-1996), Redmond, Washington.

[6] Juran, I., Baudrand, G., Farrag, K. and Elias, V. (1990), Design of Soil Nailed Retaining Structures, Design and Performance of Earth Retaining Structures, ASCE Geotechnical Special Publication, No.25, pp. 645-659.

[7] RDGC, Renforcement des Sols par Clouage: Programme Clouterre, Projects Nationaux de Recherche Developpement en Genie Civil, Paris, February. French National Research Project CLOUTERRE (1991) “Recommendations CLOUTERRE 1991 - Soil Nailing Recommendations 1991" Presses de l'Ecole Nationale des Ponts et Claussees" English Translation, July 1993. (1991)

[8] Schlosser, F., Behaviour and Design of Soil Nailing, Proceedings of Symposium on Soil and Rock Improvement Techniques, Bangkok, Thailand, 29 November -3 December 1982, pp. 399-413. (1982) 